\title{
Are the nerves supplying the anterior sacroiliac joint nociceptive?
}

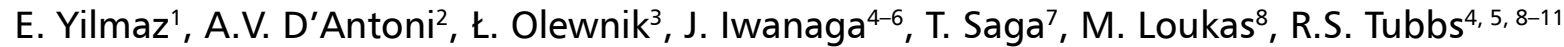 \\ ${ }^{1}$ Department of Trauma Surgery, BG University Hospital Bergmannsheil, Ruhr University Bochum, \\ Bürkle-de-la-Camp-Platz, Bochum, Germany \\ 'Wagner College, Staten Island, New York and Division of Anatomy, Department of Radiology, \\ Weill Cornell Medicine, New York, NY, United States \\ ${ }^{3}$ Department of Anatomical Dissection and Donation, Medical University of Lodz, Poland \\ ${ }^{4}$ Department of Neurology, Tulane University School of Medicine, New Orleans, LA, United States \\ ${ }^{5}$ Department of Neurosurgery, Tulane University School of Medicine, New Orleans, LA, United States \\ ${ }^{6}$ Division of Gross and Clinical Anatomy, Department of Anatomy, Kurume University School of Medicine, \\ Kurume, Fukuoka, Japan \\ ${ }^{7}$ Domain of Anatomy, Kurume University School of Nursing, Kurume, Fukuoka, Japan \\ ${ }^{8}$ Department of Anatomical Sciences, St. George's University, St. George's, Grenada, West Indies \\ ${ }^{9}$ Department of Structural and Cellular Biology, Tulane University School of Medicine, New Orleans, LA, United States \\ ${ }^{10}$ Department of Surgery, Tulane University School of Medicine, New Orleans, LA, United States \\ ${ }^{11}$ Department of Neurosurgery and Ochsner Neuroscience Institute, Ochsner Health System, \\ New Orleans, LA, United States
}

[Received: 20 December 2021; Accepted: 5 January 2022; Early publication date: 31 January 2022]

Background: Sacroiliac joint (SIJ) pain is often difficult to diagnose. Moreover, while its anatomical characteristics have been well studied, its innervation and the contributions of particular nerves remain controversial, especially in relation to posterior joint innervation. To our knowledge, previous studies have not investigated the presence of nociceptive fibres in the nerves innervating the anterior SIJ. Materials and methods: Eight adult cadaveric sides underwent dissection of the anterior SIJ. Adjacent anterior rami were examined for branches to the anterior SIJ. Any branches contributing to the anterior SIJ were measured and then resected. These samples were fixed in formalin and substance $P$ was identified immunohistologically.

Results: On all sides, 1-2 small branches (mean diameter of $0.33 \mathrm{~mm}$ ) arose from the posterior aspect of the $L 4$ anterior ramus $(12.5 \%)$, the $L 5$ anterior ramus (62.5\%), or simultaneously from both the $L 4$ and $L 5$ anterior rami (25\%). These branches had a mean length of $13.5 \mathrm{~mm}$. All histological samples contained nerve tissue. All samples of nerve fibres traveling to the anterior SIJ were positive for diffuse substance $P$ reactivity. There were no histological differences between sides or sex. Each of the branches identified as travelling to the SIJ exhibited similar positivity for substance $P$.

Conclusions: This cadaveric study demonstrates that the anterior SIJ nerve fibres carry pain fibres. This new knowledge has application to patients with SIJ syndrome and to its various treatments including interventional approaches to SIJ pain. (Folia Morphol 2023; 82, 1: 96-101)

Key words: back pain, sacroiliac joint pain, syndrome, innervation 


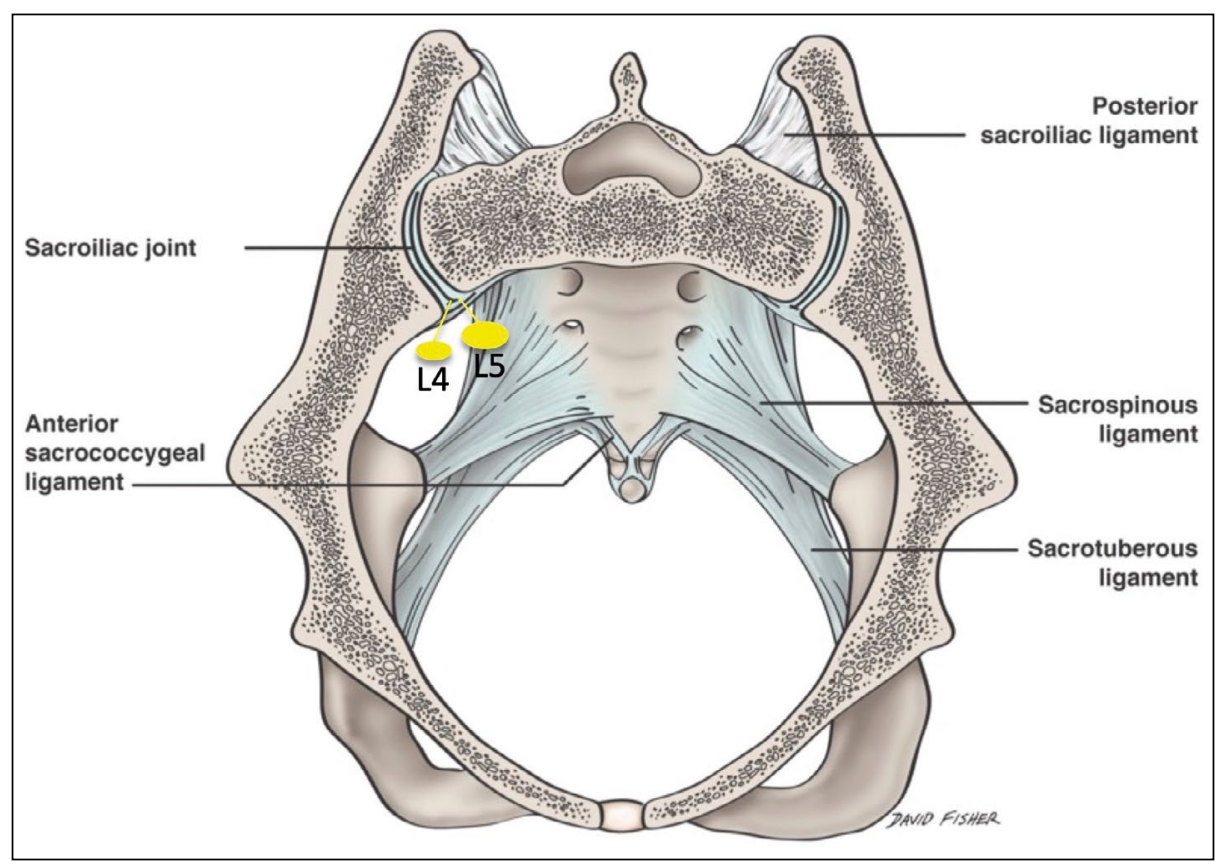

Figure 1. Superior view of the sacroiliac (SI) joint and related ligaments showing contributions from the L4 and L5 anterior rami to SI joint.

\section{INTRODUCTION}

The sacroiliac joint (SIJ) connects the sacrum to the ilium and transfers the weight from the spine to the lower extremities. While its anatomical characteristics have been well studied, SIJ innervation and the contributions of particular nerves remain controversial [6]. The SIJ has been identified as a potential cause of low back pain (LBP), and joint degeneration has been shown to be age-related and highly prevalent even in asymptomatic patients [7]. Recently, research on the SIJ as a cause and target of low back pain has intensified. The reported prevalence of SIJ dysfunction as a cause of LBP varies from $15 \%$ to $36 \%[6,29]$. SIJ-related pain is difficult to diagnose, and several different clinical tests and diagnostic blocks are used to confirm a diagnosis [11]. The clinical symptoms range from buttock pain, with or without extension to the posterolateral thigh, to pain in the area of the posterior inferior iliac spine, to lumbar pain, to pain radiating into the groin. There is no real consensus on how to diagnose SIJ-related pain $[16,17,26,30]$. Furthermore, most clinical tests of the SIJ are limited in their validity and reliability [33]. Therefore, SIJ pain scores have been developed to corroborate a diagnosis. Kurosawa et al. [25] described a score using the following criteria: one-finger test, groin pain, pain while sitting on a chair, SIJ shear test, tenderness of the posterosuperior iliac spine, and tenderness of the sacrotuberous ligament. This score has proven effec- tive for differentiating SIJ pain from any other cause of buttock pain, and provides moderate accuracy in diagnosing it [35].

Several different treatments such as physical therapy, nerve blocks, steroid injections, denervation, and ablation have been described. Treatment success ranges from $30 \%$ to $85 \%$ [6]. However, since SIJ innervation is still not fully understood, we recently studied the nerve contribution to the anterior SIJ. Previously, we demonstrated that the vast majority of nerve contributions to the anterior SIJ arise from the anterior rami of L4 or L5 (Fig. 1) [7]. However, to the best of our knowledge, there has been no immunohistological analysis of the fibre type in these branches $[2,27,32,36]$. Therefore, the purpose of this study was to identify the fibre type of the nerve branches supplying the anterior SIJ using immunohistochemistry.

\section{MATERIALS AND METHODS}

We dissected 4 fresh-frozen cadavers (8 sides) for this study. The age at death ranged from 67 to 98 years (mean 75 years). Two cadavers were male and two were female. The cadavers were positioned supine and a midline incision was made from the xiphoid process to the pubic symphysis. We split the linea alba from the subjacent peritoneum. The greater omentum was lifted upwards and the intestines and mesentery were retracted. After the 
retroperitoneal space had been carefully opened, the fascia was removed and the psoas major muscle was identified. Next, the lumbar plexus was visualised by retracting the muscle laterally. Using a surgical microscope (OPMI CS NC31, Carl Zeiss, Germany), we identified the lower lumbar anterior rami (e.g., L4, L5) and upper sacral anterior rami (e.g., S1) and the anterior SIJ. Any branches contributing to the anterior SIJ were measured with microcallipers (Mitutoyo, Japan). These samples were fixed in formalin and substance $P$ was identified immunohistologically. Substance $P$ is found in primary sensory neurons; it is a NK1 receptor agonist and belongs to the tachykinin group, which is released in response to noxious stimuli [30].

\section{Tissue preparation}

The specimens were fixed by immersion in $0.1 \mathrm{M}$ phosphate-buffered $4 \%$ formaldehyde at $4^{\circ} \mathrm{C}$. The samples were cryoprotected with $30 \%$ sucrose in phosphate buffer containing $0.9 \%$ sodium chloride supplemented with $0.15 \%$ sodium azide and were then sectioned at $50 \mu \mathrm{m}$ intervals. The sections were stored at $4^{\circ} \mathrm{C}$ pending processing. Following blocking (suppression of non-specific staining) with $2.5 \%$ normal horse serum, the sections were incubated with anti-rabbit substance $P$ (Millipore Sigma, Burlington, MA; dilution 1:1000). Following incubation, sections were rinsed with TRIS-HCl buffer, $\mathrm{pH} 7.6$, and treated with 3,3'-diamino-benzidine until the desired colour intensity was reached. Slides were mounted and allowed to dry at room temperature. Once cover-slipped, the slides were examined under a light microscope and representative images photographed.

Statistical analysis between sides and sex was performed using Student t-tests with statistical significance set at $p<0.05$.

\section{RESULTS}

On all sides, 1-2 small branches (Fig. 2) ranging in diameter from 0.28 to $0.47 \mathrm{~mm}$ (mean $0.33 \mathrm{~mm}$ ) arose from the posterior aspect of the $L 4$ anterior ramus $(n=1 ; 12.5 \%)$, the $L 5$ anterior ramus $(n=5$; $62.5 \%$ ), or simultaneously from both the $L 4$ and $L 5$ anterior rami $(n=2 ; 25 \%)$. These branches ranged from $7 \mathrm{~mm}$ to $38 \mathrm{~mm}$ long (mean $13.5 \mathrm{~mm}$ ). All histological samples were consistent with nerve tissue. No specimen showed any gross evidence of pathology or previous surgery in the areas dissected. All samples of

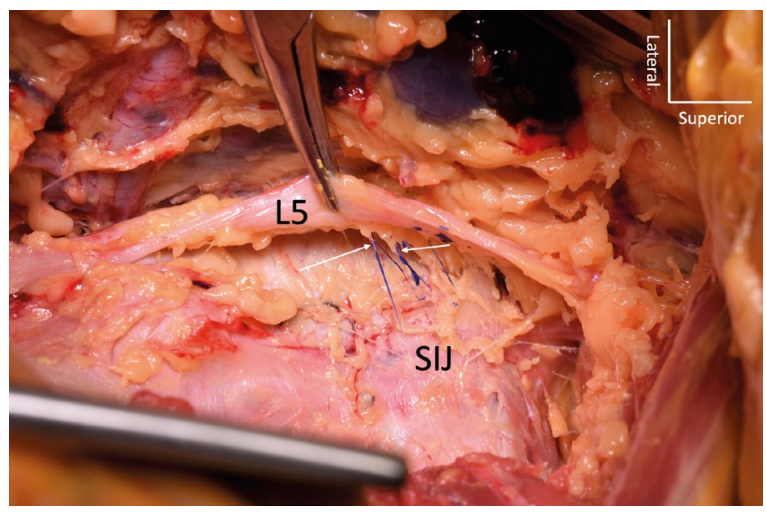

Figure 2. Cadaveric dissection of the left sacroiliac joint (SIJ) and related nerve lumbar anterior rami branches (arrows) to the SIJ.

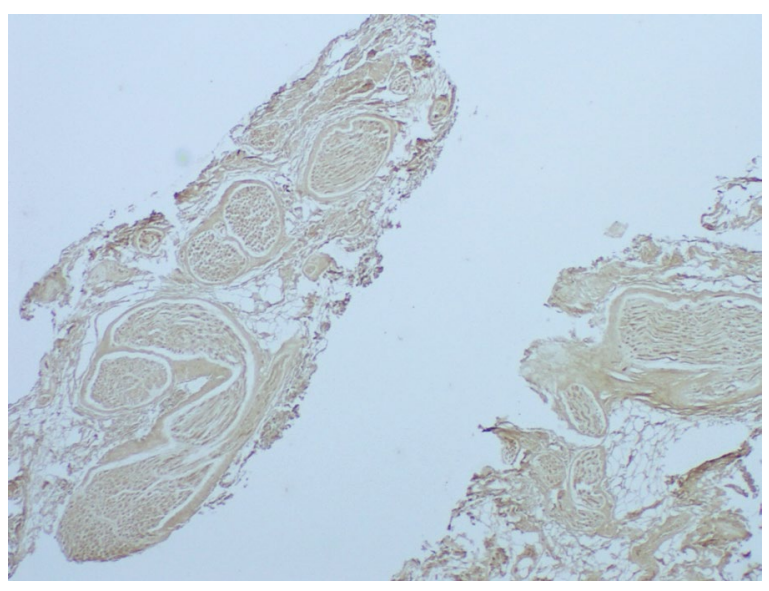

Figure 3. Histological section of two selected sacroiliac joint nerve branches noting positive reactivity for substance $\mathrm{P}(40 \times)$.

nerve fibres travelling to the anterior SIJ were positive for substance P (Fig. 3). There were no histological differences or statistical significance between sides or sex. Each of the branches identified as travelling to the SIJ exhibited similar diffuse positivity for substance $P$. All controls reacted appropriately.

\section{DISCUSSION}

The SIJ is a complex and biomechanically little-understood irregularly-shaped joint. According to Jesse et al. [22], three different surface shapes can be distinguished depending on the alpha angle. The SIJ is important in weight-bearing, load transfer and the structural stability of the pelvic girdle, which is provided mainly by the posterior sacroiliac complex ligaments forming the appearance of a suspension bridge [34]. SIJ pain can result from injury to or loosening of the ligamentous complex after trauma or inflammation [23, 24]. Minor movements resulting in 
collisions between the articulating surfaces can also regenerate pain [37].

However, innervation of the SIJ is still little understood. It is mostly accepted that the innervation derives from the anterior rami of $L 4, L 5$ and the posterior rami of L5-S3 [14, 15]. Ferrante et al. [13] were the first to report radiofrequency ablation to treat SIJ-related pain. They showed that radiofrequency ablation can significantly reduce pain even though only $36 \%$ of their patients met the criterion of at least a $50 \%$ decrease in the visual analogue pain scale. They denervated the joint by inserting three electrodes at $90^{\circ}$ starting at the inferior anterior margin and placing the two other more cephalad at $1 \mathrm{~cm}$ distances [13]. Cheng et al. [3] described a modified technique with bipolar radiofrequency by placing a continuous straight strip lesion laterally to the sacral foramina in order to denervate the L5, S1, S2 and S3 posterior rami. They observed a significantly higher rate of pain reduction (> 50\%) than with cooled radiofrequency [3]. A randomized prospective study by Dutta et al. [11] compared patients who underwent intraarticular methylprednisolone $(n=15)$ with those who underwent pulsed radiofrequency (PRF) treatment $(n=15)$ of the L4 medial branch, L5 posterior rami and the lateral sacral branches. Patients in the PRF group showed more significant pain relief and functional improvement than those in the intraarticular methylprednisolone group [11]. Vallejo et al. [38] reported 22 patients undergoing pulsed radiofrequency of the medial branch of $\mathrm{L} 4$, the posterior rami of $\mathrm{L} 5$, and the lateral branches of S1 and S2. Sixteen (72.7\%) patients reported a "good" result (pain relief $>50 \%$ in VAS). However, the duration of pain relief ranged from only 6 to 32 weeks [38]. Ding et al. [8] reported overall efficiencies of $56.3 \%$ conventional radiofrequency (CRF) and $31.3 \%$ pulsed radiofrequency (PRF) using a continuous lesion lateral to the $\mathrm{S} 1-\mathrm{S} 3$ foramina. Gevargez et al. [18] achieved similar results using computed tomography-guided intervention in 43 patients by applying CRF to the posterior rami of the $\mathrm{L} 5$ nerve and to the posterior interosseous sacroiliac ligaments. Significant pain relief was experienced by $31.6 \%$ of the patients. Cohen et al. [4] found negative correlations between age, duration of symptoms, and outcome. Patients were subjected to radiofrequency ablation of the L4-L5 posterior rami and S1-S3 lateral branches. Fifty-two per cent were considered successfully treated (pain reduction $>50 \%$ for at least 6 months) [4]. Interestingly, van Tilburg et al. [39] could not reject the hypothesis that there is no difference in pain reduction between patients who underwent radiofrequency ablation of the S1-S4 nerve root lateral branches and L5 posterior branch and patients in the placebo-treatment group. They found $42.1 \%$ pain reduction in both groups [39].

The SIJ is closely related to the lumbosacral plexus, and while the posterior SIJ is supplied by the lateral branches of the L3/L4-S3 posterior rami, the anterior joint has been said to be innervated by L2-S2 [6]. However, our more recent cadaveric study narrowed this range to $L 4$ and $L 5$ anterior rami and the findings of the present study support these earlier findings. A randomised placebo-controlled trial with 28 patients by Cohen et al. [5] showed that L4 and L5 posterior rami and S1-S3 lateral branch denervation can lead to pain relief and a functional benefit for up to 6 months post-procedure in selected patients. Different rates of success in pain relief have been reported for radiofrequency ablation, which could be related to the different techniques used, including different denervation processes, locations and targeted nerve branches [1].

Specialised peripheral sensory neurons (nociceptors) detect noxious stimuli and mediate pain [10]. Nociceptive fibres are classified according to their sensitivity to heat, cold and noxious mechanical stimuli. Most nociceptors have unmyelinated axons (C-fibres) with small diameter, which is directly correlated with the transmission speed. In contrast, initial 'fast-onset' pain is mediated not by C-fibres, but by A-fibres with myelinated axons [9]. Debate about innervation of the SIJ continues. However, several studies support the assumption that nociceptive signals originate directly from the SIJ. A histological study of neural elements of the human SIJ $(n=6)$ by Vilensky et al. [40] revealed mechanoreceptors, nerves and nerve fascicles. Grob et al. [19] found myelinated and unmyelinated fibres in the joint. Ikeda et al. [20] reported nerve diameters ranging from 0.2 to $2.5 \mu \mathrm{m}$, which puts the nerve in the range of C- and A-delta fibres [37]. There are substance $P$ and calcitonin gene-related polypeptide positive fibres, associated with nociception, in the SIJ and surrounding ligaments. Szadek et al. [32] revealed substance $P$ and CGRP positive fibre-like structures in their cartilage tissue samples from 10 human cadavers. Sakamoto et al. [28] identified mechanosensitive afferent units in the SIJ and adjacent tissues.

Eno et al. [12] showed that SIJ degeneration is age-related and highly prevalent even in asymptot- 
ic patients. Furthermore, Suri et al. [31] observed growth of neurovascular tissue in human knees with advanced osteoarthritis. Whether these results are associated with joint degeneration or are valid for non-degenerated SIJs has yet to be determined.

\section{CONCLUSIONS}

This cadaveric study demonstrates that the anterior SIJ nerve fibres carry pain fibres. This new knowledge has application to patients with SIJ syndrome and to its various treatments including interventional approaches to SIJ pain.

\section{Acknowledgements}

The authors sincerely thank those who donated their bodies to science so that anatomical research could be performed. Results from such research can potentially increase mankind's overall knowledge that can then improve patient care. Therefore, these donors and their families deserve our highest gratitude [21].

\section{Conflict of interest: None declared}

\section{REFERENCES}

1. Aydin SM, Gharibo CG, Mehnert M, et al. The role of radiofrequency ablation for sacroiliac joint pain: a meta-analysis. PM R. 2010; 2(9): 842-851, doi: 10.1016/j. pmrj.2010.03.035, indexed in Pubmed: 20869684.

2. Castañeda-Corral G, Jimenez-Andrade JM, Bloom AP, et al. The majority of myelinated and unmyelinated sensory nerve fibers that innervate bone express the tropomyosin receptor kinase A. Neuroscience. 2011; 178: 196-207, doi: 10.1016/j.neuroscience.2011.01.039, indexed in Pubmed: 21277945.

3. Cheng J, Chen SL, Zimmerman N, et al. A new radiofrequency ablation procedure to treat sacroiliac joint pain. Pain Physician. 2016; 19(8): 603-615, indexed in Pubmed: 27906939.

4. Cohen SP, Strassels SA, Kurihara C, et al. Outcome predictors for sacroiliac joint (lateral branch) radiofrequency denervation. Reg Anesth Pain Med. 2009; 34(3): 206-214, doi: 10.1097/AAP.0b013e3181958f4b, indexed in Pubmed: 19587617.

5. Cohen SP, Hurley RW, Buckenmaier CC, et al. Randomized placebo-controlled study evaluating lateral branch radiofrequency denervation for sacroiliac joint pain. Anesthesiology. 2008; 109(2): 279-288, doi: 10.1097/ ALN.0b013e31817f4c7c, indexed in Pubmed: 18648237.

6. Cohen SP, Chen Y, Neufeld NJ. Sacroiliac joint pain: a comprehensive review of epidemiology, diagnosis and treatment. Expert Rev Neurother. 2013; 13(1): 99-116, doi: 10.1586/ern.12.148, indexed in Pubmed: 23253394.

7. Cox M, Ng G, Mashriqi F, et al. Innervation of the anterior sacroiliac joint. World Neurosurg. 2017; 107: 750-752, doi: 10.1016/j.wneu.2017.08.062, indexed in Pubmed: 28838880

8. Ding $Y$, Li H, Yao P, et al. Clinical observation of CT-guided intra-articular conventional radiofrequency and pulsed radiofrequency in the treatment of chronic sacroiliac joint pain. J Pain Res. 2018; 11: 2359-2366, doi: 10.2147/JPR. S179712, indexed in Pubmed: 30410388.

9. Djouhri L, Lawson SN. Abeta-fiber nociceptive primary afferent neurons: a review of incidence and properties in relation to other afferent A-fiber neurons in mammals. Brain Res Brain Res Rev. 2004; 46(2): 131-145, doi: 10.1016/j. brainresrev.2004.07.015, indexed in Pubmed: 15464202.

10. Dubin AE, Patapoutian A. Nociceptors: the sensors of the pain pathway. J Clin Invest. 2010; 120(11): 3760-3772, doi: 10.1172/JCl42843, indexed in Pubmed: 21041958.

11. Dutta K, Dey S, Bhattacharyya P, et al. Comparison of efficacy of lateral branch pulsed radiofrequency denervation and intraarticular depot methylprednisolone injection for sacroiliac joint pain. Pain Physician. 2018; 21(5): 489-496, indexed in Pubmed: 30282393.

12. Eno JJT, Boone CR, Bellino MJ, et al. The prevalence of sacroiliac joint degeneration in asymptomatic adults. J Bone Joint Surg Am. 2015; 97(11): 932-936, doi: 10.2106/JBJS.N.01101, indexed in Pubmed: 26041855.

13. Ferrante FM, King LF, Roche EA, et al. Radiofrequency sacroiliac joint denervation for sacroiliac syndrome. Reg Anesth Pain Med. 2001; 26(2): 137-142, doi: 10.1053/ rapm.2001.21739, indexed in Pubmed: 11251137.

14. Forst SL, Wheeler MT, Fortin JD, et al. The sacroiliac joint: anatomy, physiology and clinical significance. Pain Physician. 2006; 9(1): 61-67, indexed in Pubmed: 16700283.

15. Vilensky JA, O'Connor BL, Fortin JD, et al. Sacroiliac joint innervation and pain. Am J Orthop (Belle Mead NJ). 1999; 28(12): 687-690, indexed in Pubmed: 10614759.

16. Fortin JD, Dwyer AP, West $S$, et al. Sacroiliac joint: pain referral maps upon applying a new injection/arthrography technique. Part I: Asymptomatic volunteers. Spine (Phila Pa 1976). 1994; 19(13): 1475-1482, indexed in Pubmed: 7939978.

17. Fortin JD, Aprill CN, Ponthieux B, et al. Sacroiliac joint: pain referral maps upon applying a new injection/arthrography technique. Part II: Clinical evaluation. Spine (Phila Pa 1976). 1994; 19(13): 1483-1489, indexed in Pubmed: 7939979.

18. Gevargez A, Groenemeyer D, Schirp S, et al. CT-guided percutaneous radiofrequency denervation of the sacroiliac joint. Eur Radiol. 2002; 12(6): 1360-1365, doi: 10.1007/ s00330-001-1257-2, indexed in Pubmed: 12042940.

19. Grob KR, Neuhuber WL, Kissling RO. [Innervation of the sacroiliac joint of the human]. Z Rheumatol. 1995; 54(2): 117-122, indexed in Pubmed: 7793158.

20. Ikeda R. [Innervation of the sacroiliac joint. Macroscopical and histological studies]. Nihon Ika Daigaku Zasshi. 1991; 58(5): 587-596, doi: 10.1272/jnms1923.58.587, indexed in Pubmed: 1744230.

21. Iwanaga J, Singh V, Ohtsuka A, et al. Acknowledging the use of human cadaveric tissues in research papers: recommendations from anatomical journal editors. Clin Anat. 2021; 34(1): 2-4, doi: 10.1002/ca.23671, indexed in Pubmed: 32808702.

22. Jesse MK, Kleck C, Williams A, et al. 3D morphometric analysis of normal sacroiliac joints: a new classification of 
surface shape variation and the potential implications in pain syndromes. Pain Physician. 2017; 20(5): E701-E709, indexed in Pubmed: 28727714.

23. Kim YH, Yao Z, Kim K, et al. Quantitative investigation of ligament strains during physical tests for sacroiliac joint pain using finite element analysis. Man Ther. 2014; 19(3): 235-241, doi: 10.1016/j.math.2013.11.003, indexed in Pubmed: 24378472.

24. Kloppers FJ, van der Merwe JF, van Zyl AA. Sacroiliac screw versus locking square plate fixation in sacroiliac joint disruption on composite bone models: a descriptive comparative biomechanical study. Transl Res Anat. 2022; 26: 100156, doi: 10.1016/j.tria.2021.100156.

25. Kurosawa D, Murakami E, Ozawa $H$, et al. A diagnostic scoring system for sacroiliac joint pain originating from the posterior ligament. Pain Med. 2017; 18(2): 228-238, doi: 10.1093/pm/pnw117, indexed in Pubmed: 28204687.

26. Murakami E, Aizawa T, Noguchi K, et al. Diagram specific to sacroiliac joint pain site indicated by one-finger test. J Orthop Sci. 2008; 13(6): 492-497, doi: 10.1007/s00776008-1280-0, indexed in Pubmed: 19089535.

27. Ruscheweyh R, Forsthuber L, Schoffnegger D, et al. Modification of classical neurochemical markers in identified primary afferent neurons with Abeta-, Adelta-, and C-fibers after chronic constriction injury in mice. J Comp Neurol. 2007; 502(2): 325-336, doi: 10.1002/cne.21311, indexed in Pubmed: 17348016.

28. Sakamoto N, Yamashita T, Takebayashi T, et al. An electrophysiologic study of mechanoreceptors in the sacroiliac joint and adjacent tissues. Spine (Phila Pa 1976). 2001; 26(20): E468-E471, doi: 10.1097/00007632-20011015000008, indexed in Pubmed: 11598526.

29. Simopoulos TT, Manchikanti L, Gupta S, et al. A systematic evaluation of the therapeutic effectiveness of sacroiliac joint interventions. Pain Physician. 2012; 15(3): E247-E278, indexed in Pubmed: 22622913.

30. Slipman CW, Jackson HB, Lipetz JS, et al. Sacroiliac joint pain referral zones. Arch Phys Med Rehabil. 2000; 81(3): 334-338, doi: 10.1016/s0003-9993(00)90080-7, indexed in Pubmed: 10724079.

31. Suri S, Gill SE, Massena de Camin S, et al. Neurovascular invasion at the osteochondral junction and in osteophytes in osteoarthritis. Ann Rheum Dis. 2007; 66(11): 1423-1428, doi: 10.1136/ard.2006.063354, indexed in Pubmed: 17446239.
32. Szadek KM, Hoogland PV, Zuurmond WWA, et al. Possible nociceptive structures in the sacroiliac joint cartilage: an immunohistochemical study. Clin Anat. 2010; 23(2): 192-198, doi: 10.1002/ca.20908, indexed in Pubmed: 20014392.

33. Telli H, Telli S, Topal M. The validity and reliability of provocation tests in the diagnosis of sacroiliac joint dysfunction. Pain Physician. 2018; 21(4): E367-E376, indexed in Pubmed: 30045603.

34. Tile M. Pelvic ring fractures: should they be fixed? J Bone Joint Surg Br. 1988; 70(1): 1-12, doi: 10.1302/0301-620X.70B1.3276697, indexed in Pubmed: 3276697.

35. Tonosu J, Oka H, Watanabe K, et al. Validation study of a diagnostic scoring system for sacroiliac joint-related pain. J Pain Res. 2018; 11: 1659-1663, doi: 10.2147/JPR. S167033, indexed in Pubmed: 30214275.

36. van Rossum D, Hanisch UK, Quirion R. Neuroanatomical localization, pharmacological characterization and functions of CGRP, related peptides and their receptors. Neurosci Biobehav Rev. 1997; 21(5): 649-678, doi: 10.1016/ s0149-7634(96)00023-1.

37. Vleeming A, Schuenke MD, Masi AT, et al. The sacroiliac joint: an overview of its anatomy, function and potential clinical implications. J Anat. 2012; 221(6): 537-567, doi: 10.1111/j.1469-7580.2012.01564.x, indexed in Pubmed: 22994881.

38. Vallejo R, Benyamin RM, Kramer J, et al. Pulsed radiofrequency denervation for the treatment of sacroiliac joint syndrome. Pain Med. 2006; 7(5): 429-434, doi: 10.1111/j.1526-4637.2006.00143.x, indexed in Pubmed: 17014602.

39. van Tilburg CWJ, Schuurmans FA, Stronks DL, et al. Randomized sham-controlled double-blind multicenter clinical trial to ascertain the effect of percutaneous radiofrequency treatment for sacroiliac joint pain: threemonth results. Clin J Pain. 2016; 32(11): 921-926, doi: 10.1097/AJP.0000000000000351, indexed in Pubmed: 26889616.

40. Vilensky JA, O'Connor BL, Fortin JD, et al. Histologic analysis of neural elements in the human sacroiliac joint. Spine (Phila Pa 1976). 2002; 27(11): 1202-1207, doi: 10.1097/00007632-200206010-00012, indexed in Pubmed: 12045518. 